\title{
La elocuencia de la pintura. Las puertas del archivo de la Universidad de Salamanca*
}

\author{
The Eloquence of Painting. The Doors of the University of \\ Salamanca's Archive
}

\section{Lucía Lahoz ${ }^{1}$}

Universidad de Salamanca

\begin{abstract}
Resumen: Las pinturas de Martín de Cervera en las puertas del archivo de la Universidad de Salamanca, ubicado en 1613 en la Casa del Bedel, conforman un rico mensaje intervisual, dispuesto en distintos registros modales: narrativo, emblemático, heráldico, alegórico y epigráfico. Testimonian audiencias y prácticas docentes en las cátedras de Leyes y Teología, normas y disputas universitarias, en una representación que modula el registro sigilar del Estudio del siglo XVI, reforzando su promoción monárquica. Traducido a modelo narrativo, este sello subraya el carácter secreto del archivo y advierte de la inviolabilidad de los documentos en el ceremonial aurático de apertura del mueble que, cuando se cierra, sella -real y metafóricamente- con esta impronta, el lugar donde se custodia la matriz. Un documento figurativo imprescindible en la construcción del relato institucional universitario.
\end{abstract}

Palabras clave: Salamanca; Archivo; imagen sigilar; epigrafía, cultura visual; puertas figuradas.

Abstract: Martín de Cervera's paintings on the doors of the University of Salamanca's archive, located in 1613 in the Casa del Bedel, conform a rich intervisual message trasferred to different modal records: narrative emblematic, heraldic, allegorical and epigraphic. The paintings testimony audiences and teaching practices in the chairs of Law and Theology, university norms and disputes, in a representation that modulate the sigilar record of the sixteenth century Estudio, reinforcing its monarchical promotion. Translated into a narrative model, this seal underlines the secret nature of the archive and warns of the inviolability of the documents in it, during the

\footnotetext{
* Este trabajo se inscribe dentro del proyecto de Investigación MINECO, Intermedialidad e institución. Relaciones interartísticas, literatura, audiovisual y artes plásticas. HAR201785392-P

1 () http://orcid.org/0000-0002-9184-9960
}

(C) 2021 Philostrato. Revista de Historia y Arte 
ceremonial opening of the furniture that, when is closed, seals -real and metaphorically- with this stamp, the place where the matrix of the seal is guarded. It is an essential figurative document in the construction of the institutional university account.

Keywords : Salamanca; Archive Sigil Image; Epigraphy; Visual Culture; Figured doors.

\title{
1. Ámbitos y docencia
}

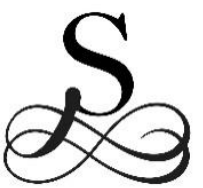

i, como proponía Warburg, se han de utilizar los testimonios visuales como documentos históricos, pocas veces nos es dado asistir tan en directo a unas aulas y presenciar el discurrir de una clase del siglo XVII en la Universidad de Salamanca, como a través de la composición que Martín de Cervera pintara para signar el armario del archivo antes de $1614^{2}$.

En las puertas del mueble se representan, entre otros iconogramas, dos generales, que se corresponden con las aulas de leyes y de teología (Fig. 1). En la de Teología, un dominico dicta la lección ante una audiencia que copia con atención; una actitud que refleja fielmente el cambio en la pedagogía universitaria. Durante el curso 1539-1540, el tomista Francisco de Vitoria ya defendió la práctica del 'dictado' en sus clases. Como subrayó Pereda, el maestro Vitoria había puesto en marcha una pequeña revolución.

\begin{abstract}
"De lo que se trataba era que el profesor permitía que sus alumnos copiaran palabra por palabra sus lecciones, según las iba hilvanado desde la cátedra, de tal manera que se establecía una relación directa entre lo proferido en voz alta y lo que luego circulaba en los apuntes. Pronto se puso de moda esa costumbre y los alumnos acudían a clase con papel y tintero, presionando para que se impusiera ese cambio a pesar de las negativas de las propias autoridades universitarias que argumentaban que supondría el final del ejercicio de la memoria. De hecho, en los estatutos de 1561 se prohibía expresamente su práctica. Finalmente, pese a las reticencias ganaron los estudiantes y el dictado era cosa admitida"3.
\end{abstract}

Así lo demuestra la tabla de Cervera, donde el artista despliega a los estudiantes sentados en un mobiliario incómodo y poco apropiado para ello, pero dispuestos de papel y pluma para recoger con puntos y comas la lección que pronuncia un fraile desde su cátedra, mientras que sostiene un libro en

\footnotetext{
2 Emilia Montaner López, Pintura barroca en Salamanca, (Salamanca: Ediciones Universidad de Salamanca), 1987, p.34. Nos hemos ocupado de ello en Lucía Lahoz, "Puerta de la sala de manuscritos (Martín de Cervera)", en El Barroco en Salamanca, eds. José María Martínez Frías, Manuel, Hernández Pérez y Lucía Lahoz, (Salamanca: Junta Castilla y León, 2008), p. 104.

${ }^{3}$ Felipe Pereda, La arquitectura elocuente. El edificio de la Universidad de Salamanca bajo el reinado de Carlos V, (Madrid: Sociedad Estatal para la Conmemoración de los Centenarios de Felipe II y Carlos V, 2000) p. 135 y ss.
} 


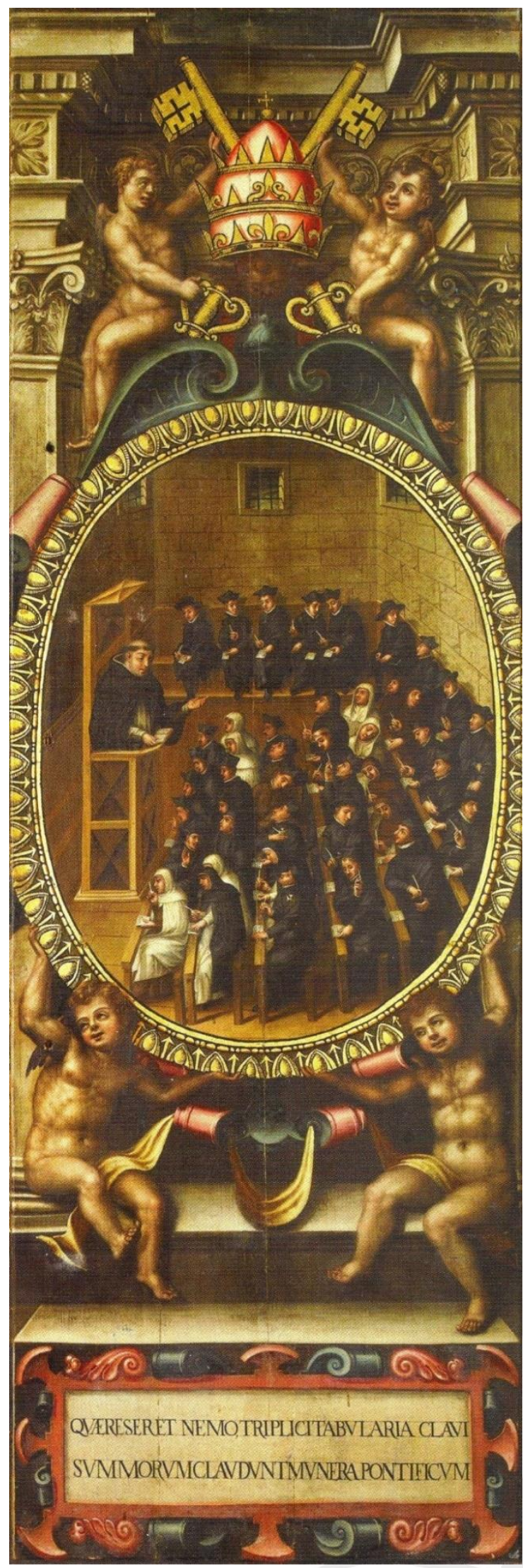

Fig. 1. Martín de Cervera, Aula de Teología. Puertas del archivo. Universidad de Salamanca () Foto Santiago Santos. 
la mano derecha. Práctica que, según Pereda, es un episodio más en el establecimiento de una civilización del escrito dando al traste con el protagonismo que la oralidad había desempeñado en la cultura medieval ${ }^{4}$. Además, el problema y las reticencias habían afectado principalmente a las clases de Teología, y precisamente es en el general de los teólogos donde se figura la nueva situación. La pintura testimonia que la práctica del apunte es un hecho contrastado y su elección y presencia en las tablas del archivo -una obra promovida por la propia universidad, como se verá- lo corrobora. Se está, en ese caso, ante uno de los valores de la imagen como documento histórico, como también defendió Burke ${ }^{5}$. Asimismo, se trata de un buen ejemplo de su valor como testimonios de las fases pasadas, por medio de las cuales se pueden leer las estructuras del pensamiento y la representación de una determinada época, como sostuvo Burckhardt. Por su parte, Le Goff consideraba que "la imagen juega un doble papel, de documento casi objetivo y de documento del imaginario"6. En efecto, a través de las pinturas de Cervera se imagina mejor el discurrir de la vida universitaria en el siglo XVII. Se trata, a fin de cuentas, de aprovechar "las múltiples posibilidades de las imágenes como fuente histórica y como recurso para escribir la historia", por utilizar las palabras de Mazin Gómez. ${ }^{7}$

El contenido de la figuración del aulario no se limita a lo expuesto, articula una información más amplia. En los respectivos recintos se detectan algunos contrastes con diferencias de alcance que han pasado inadvertidos. Se trata de los generales, así llamadas a las aulas donde se leen las lecciones públicas, por ser comunes a todos los que quisieran entrar a oír en ellas, como declaraba Covarrubias en su Tesoro de la legua castellana ${ }^{8}$. De partida, la elección de un dominico para dictar la clase de teología delata el protagonismo de los hermanos de Santo Domingo para ocupar esas cátedras, constatada desde sus inicios, que compartían con los franciscanos para acabar finalmente por monopolizarlas. Vestido con el hábito de la orden, se coloca de perfil. En el aula de leyes el profesor figura de frente, va investido de doctor, tocado con el bonete e incluso se recorta su silueta sobre una rica tela, posiblemente de terciopelo, acaso un tapiz que refuerza su significado. No resulta baladí el recurso a tales distinciones, se notarán las diferencias ontológicas entre la figuración de frente y de perfil, me pregunto si tal contraste no responde a modos de composición que sirven para trasmitir una dualidad de significados y las diferencias de rango, de posición y de jerarquía, como magistralmente señalara Schapiro.

\footnotetext{
${ }^{4}$ Pereda, Arquitectura elocuente, p. 135 y ss.

5 Peter Burke, Visto y no visto. El uso de la imagen como documento histórico, (Barcelona: Crítica, 2001).

6 Jacques Le Goff, "Discours de clôture", Le Travail au Moyen Âge. Une approche interdisciplinaire, Actes du colloque international de Louvain-la-Neuve, mai 1987, Louvain-la-Neuve, (Louvain : Publications de l'Institut d'Etudes Médiévales, 1990) pp. 418-419.

7 Oscar Mazin Gómez, "Presentación. Las imágenes y el historiador", Relaciones, 77, Vol. XX, (1999), p. 11.

${ }^{8}$ Sebastian de Covarrubias, Tesoro de la lengua castellana, 1611 entrada aula fol. 104.

9 Meyer Schapiro, "Frontal y perfil como forma simbólica" en Palabras, escritos e imágenes, (Madrid: Ed. Encuentro, 1996), p. 65.
} 


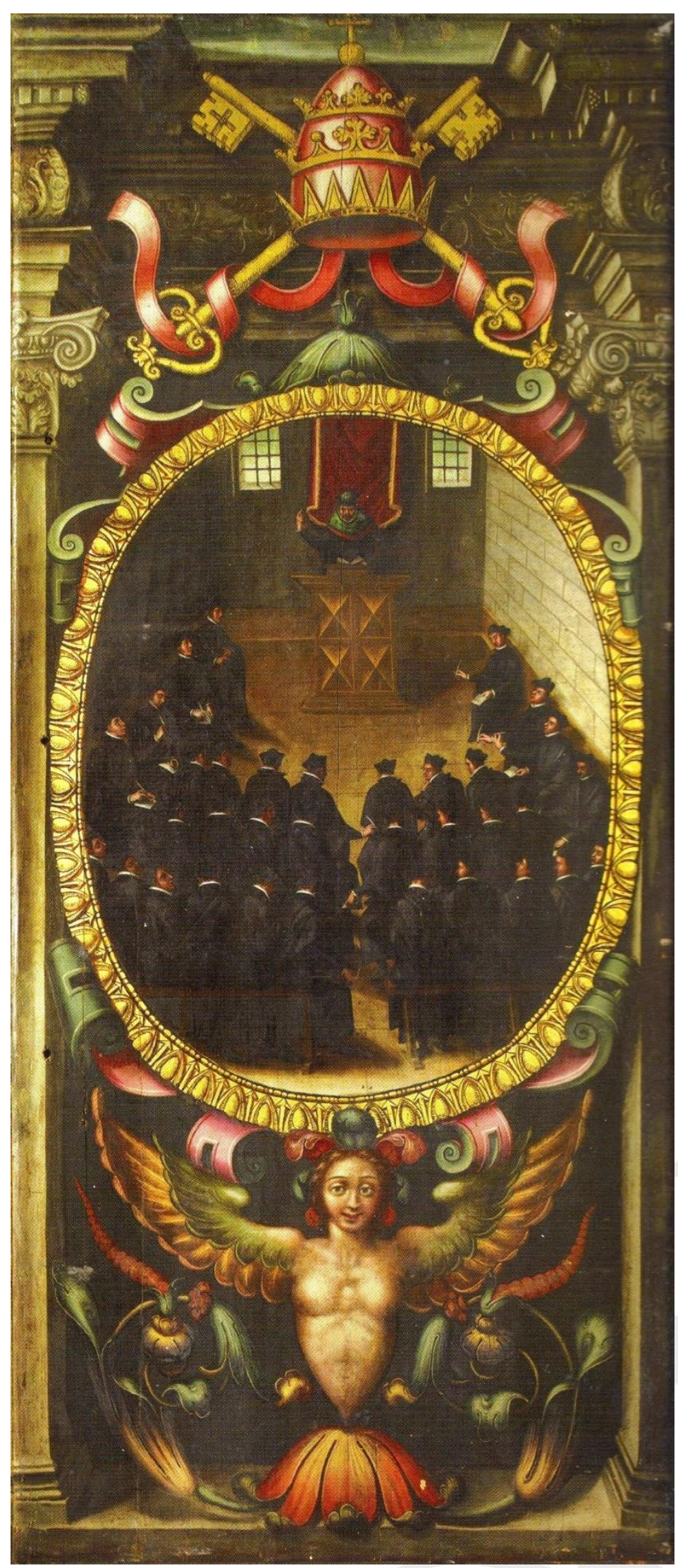

Fig. 2. Martín de Cervera, Aula de Leyes. Puertas del archivo, Universidad de Salamanca, (c Foto Santiago Santos. 
La representación de las respectivas cátedras también difiere; la de Teología es el mueble con tornavoz, que se ha relacionado con la que todavía se conserva en la actual "aula de Fray Luis", con la que mantiene una comunidad evidente, mientras que para la de cánones se prefiere un púlpito con atril y se trasdosa con el tapiz que subraya la categoría y la dignifica, sabido el significado de la tapicería, tenía el cometido de revestir y dar calidez a los muros, funcionaba como símbolo de estatus, añadiendo capas de sentido e ideología a la arquitectura ${ }^{10}$. Las discordancias responden a un interés en subrayar prioridades; que en este sistema de representación las Leyes salen beneficiadas es notable, que por otra parte coincide con la proyección que en esos momentos ha adquirido el Derecho en el estudio salmantino, dado que la universidad del siglo XVI y XVII es una universidad de juristas (Fig. 2).

Las divergencias no resultan azarosas, sino que refuerzan la respectiva trascendencia. $Y$ esas diferencias de frente y perfil deben estar repletas de significado. Los bancales también difieren, para la primera se ha evocado el tipo de pupitre corrido como en el "aula de Fray Luis", que no figuran en la segunda. Sin embargo, ambas tienen en común el banco corrido que anima y acomoda en los muros perimetrales.

La pintura proporciona igualmente datos precisos sobre la naturaleza de los asistentes, con un despliegue de sotanas, manteos y bonetes como prescribía la normativa universitaria. Según ha señalado Rodríguez-San Pedro, se pueden distinguir entre ellos clérigos regulares, estudiantes comunes, o criados con sombrero, caballeros de ordenes militares, algunos colegiales mayores (posiblemente de San Bartolomé) y un rosario de dominicos o trinitarios, bernardos, mercedarios, premostratenses, agustinos y carmelitas ${ }^{11}$. Sobre el negro dominante de los trajes, las golas blancas y los puños introducen una nota de color, de mayor contraste si cabe.

Las diferencias también afectan a la distribución de los estudiantes: mientras que los aprendices de teólogos se colocan en las más diversas actitudes de frente, de perfil, los futuros canonistas se fijan en su inmensa mayoría de espaldas, apostando por un modelo semiótico repleto de significado. La figura de espalda constituye una metáfora visual de la duda, perfectamente adecuada para la formación de los letrados, no tanto para los teólogos. La normativa universitaria prohibía dar la espalda al profesor, y sin embargo en la figuración del aula de teología sí se fija de esa guisa algún estudiante, introduciendo un tono hasta anecdótico. Todo parece indicar que

\footnotetext{
10 Elena Muñoz, "Tapicería troyana en Zamora... 'Y otras cosas ançianas que hayan sido de nuestros abuelos y bisabuelos'", en Humanistas, helenistas y hebraístas en la Europa de Carlos $V$, coords. Miguel Anxo Pena González e Inmaculado Delgado Jara, (Salamanca: Universidad Pontificia de Salamanca, 2019), p. 413.

${ }_{11}$ Luis Enrique Rodríguez-San Pedro, "Vida estudiantil en el siglo de Oro" en Estudiantes de Salamanca, eds. Luis Enrique Rodríguez-San Pedro y Roberto Martínez del Río, (Salamanca: Ediciones Universidad de Salamanca, 2001), p. 60.
} 
las respectivas disposiciones, lejos de ser aleatorias, están perfectamente elegidas y cuidadas, dado el contenido que suscriben.

Asimismo, la obra reporta un auténtico documento visual del tipo de aula vigente en el estudio salmantino por ese tiempo. Describe un espacio uniforme, rectangular, con bancos corridos en el centro y también circundando los muros perimetrales para ampliar la capacidad de la audiencia. Modelo y tipología de notable tradición en la universidad salmantina, de hecho, en la documentación en 1378 cuando se inician los arreglos de la primera aula, previa al edificio actual, se formula un tipo similar, como sucede con el adecentamiento para las escuelas de Decreto ${ }^{12}$; lo cual nos habla de una tradición bien asentada, por adecuarse perfectamente a las necesidades funcionales docentes. El ámbito se ilumina con ventanas altas que conforman una suerte de penumbra, que debió ser la habitual del recinto universitario, toda vez que protege y evita la distracción del alumnado.

Esa diferenciación y mayor solemnidad de los canonistas coincide y transcribe la propia dinámica de la universidad en su momento, donde la fama y la proyección recaían en la enseñanza del Derecho, seguida en segundo lugar por la Teología. Ni que decir tiene que esta pintura de las puertas constituye un interesante testimonio documental figurativo que nos ayuda a imaginar el pasado de una manera más viva, cuyo interés se magnifica, si cabe, dada su excepcionalidad.

\section{Sobre el programa el iconográfico}

Estas aulas acogidas en tondos ovalados, rematados por ovas, lucen cual trofeos sostenidos por puttis, enmarcados en unas arquitecturas suntuosas que otorgan empaque a la composición. Las armas pontificias emblemáticamente expuestas los rematan. Los motivos figurativos descritos se completan con sendas tablas donde se exhiben ostentosamente los escudos coronados de la monarquía, detallados los reinos y circundado por el toisón de oro; se concreta pues una composición ovalada similar a las vecinas. En el que se corresponde con el general de cánones, unos ángeles sujetan las armas heráldicas, los de la parte superior portan la corona de olivo, una cuerda y una espada, en los inferiores señalan un yelmo; acaso haga alusión a la formación de grandes hombres al servicio de la corona, siguiendo los recursos de la emblemática. De hecho, la espada es el símbolo de la justicia. Para el segundo, aquel que coincidía con el aula de teología, está rematada por la alegoría de la Fe (Fig. 3).

\footnotetext{
12 Nos hemos ocupado de ello en Lucía Lahoz, "La primera imagen universitaria salmantina, ¿Entre la vindicación pontificia y la poética mudéjar?", en Imagen, contextos morfológicos y universidades. Miscelánea Alfonso IX, eds. L. E. Rodríguez San Pedro-Bezares y J. L. Polo Benito, (Salamanca: Universidad de Salamanca, 2012), pp. 69-119.
} 


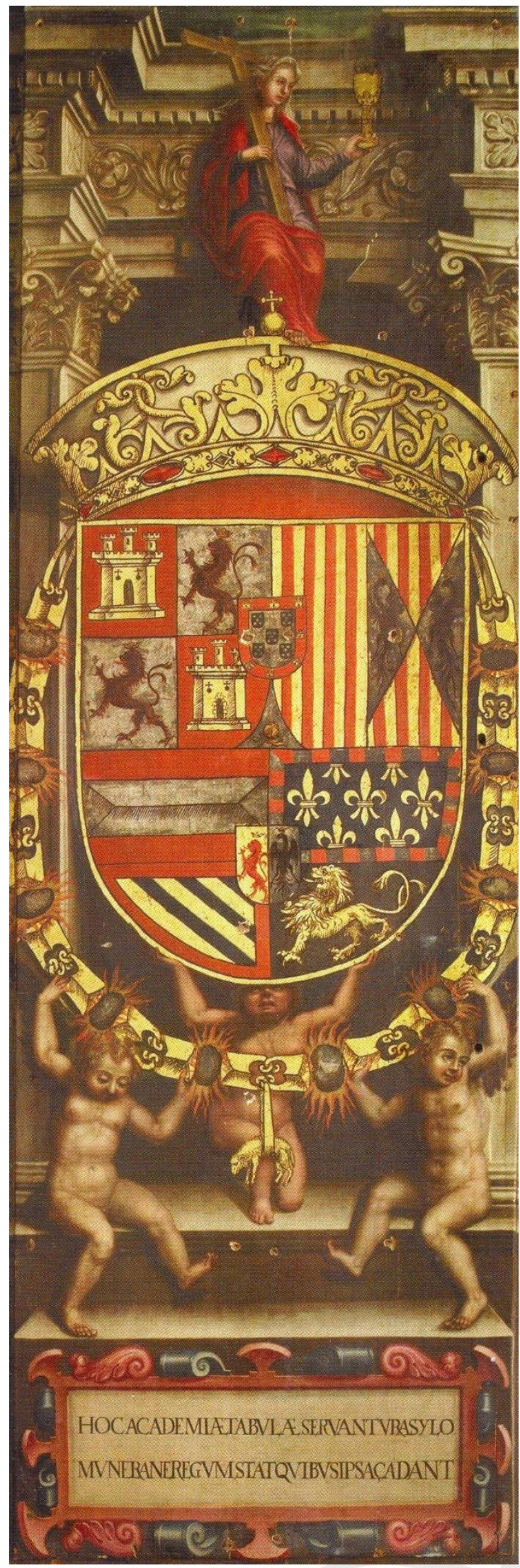

Fig. 3. Martín de Cerver, Escudo real trasdosado por la alegoría de la Fe. Puertas del archivo. Universidad de Salamanca, (c) Foto Santiago Santos. 
No hay unanimidad a la hora de definir el sentido del trasunto iconográfico. Se ha interpretado como el escudo de la universidad y las armas reales, según ya señalará Huarte: "en unas puertas se representa las armas reales y el escudo de la universidad y con las armas pontificias en la parte superior y en la inferior siguiendo los usos de la sigilografía el emblema alusivo al organismo al que se otorgaban ${ }^{13}$. Se notará cómo, ya Huarte, lo describe como el escudo universitario, pero con cierta ambivalencia apela al concepto sigilar y lo introduce en la definición. De todos modos, la importancia concedida a esas escenas didascálicas ha impedido interpretarlo en su totalidad, si bien Jaramillo lo suponía como el escudo universitario: "En realidad lo que se representa no es sino el escudo de la universidad, desglosado con una finalidad muy clara, a un lado la autoridad pontificia sobre el estudio y los estudiantes y al otro el amparo regio"14.

A pesar de la insistencia en interpretarlo como la representación del escudo universitario, como ya señaló Domínguez Casas, la academia salmantina no tuvo escudo, sino que fue el registro sigilar, más o menos desarrollado el que sirvió como medio de identificación ${ }^{15}$. La composición elegida coincide con los motivos icónicos que componen la representación del sello universitario, si bien, dada la naturaleza del soporte, se apuesta por un modelo narrativo y duplicado. Sin embargo, se modifica el motivo sigilar figurado, se abandona el primer modelo presidido por el papa, con las armas pontificias y reales, para elegir el segundo tipo donde la autoridad papal es sustituida por el profesor en la cátedra, como figuraba en algunos sellos del siglo XVI, donde se prefiere al catedrático dictando la lectio. Tal vez la modificación venga impuesta por el mayor protagonismo de la monarquía. Transformaciones que, más allá de una simple variación, articulan modelos de intención y en ellas pervive parte de la historia universitaria. Ese poder de la Corona en las tablas queda perfectamente resaltado.

A la imaginería real se le concede un mayor protagonismo en la composición: la heráldica de la monarquía ha perdido ese papel secundario y, por tamaño, queda en el centro del conjunto, compartiendo espacio con las aulas (Fig. 4). Las armas pontificias rematan las escenas docentes. Se concreta así una alusión extraordinaria a los respectivos poderes y el significado de ambos. Esos elementos integran y componen en su totalidad el sello universitario, si bien exhiben un desarrollo narrativo más amplio, pero, al fin y al cabo, da buena cuenta del peso icónico del registro sigilar.

\footnotetext{
13 Amalio Huarte y Echenique, El archivo universitario de Salamanca, (Salamanca: Ateneo, 1916), p. 8; Agustín Vivas, "El Archivo Histórico de la Universidad de Salamanca: Historia y procedencias documentales", Documentación de las ciencias de información, no. 22, (1999), p. 123.

${ }_{14}$ Miguel Ángel Jaramillo Guerreiro, "El Archivo de la universidad de Salamanca: Historia de una larga gestación", en Fuentes, archivos y bibliotecas para una historia de las universidades hispánicas, ed. Luis Enrique Rodríguez-San Pedro Bezares, (Salamanca: Ediciones Universidad de Salamanca, 2014), p.179. ${ }^{15}$ Rafael Domínguez Casas, Imago pintiana. Heráldica, Emblemas y Fastos de la Universidad de Valladolid. (s. XVI-XXI), (Valladolid: Universidad de Valladolid, 2012), p. 45.
} 


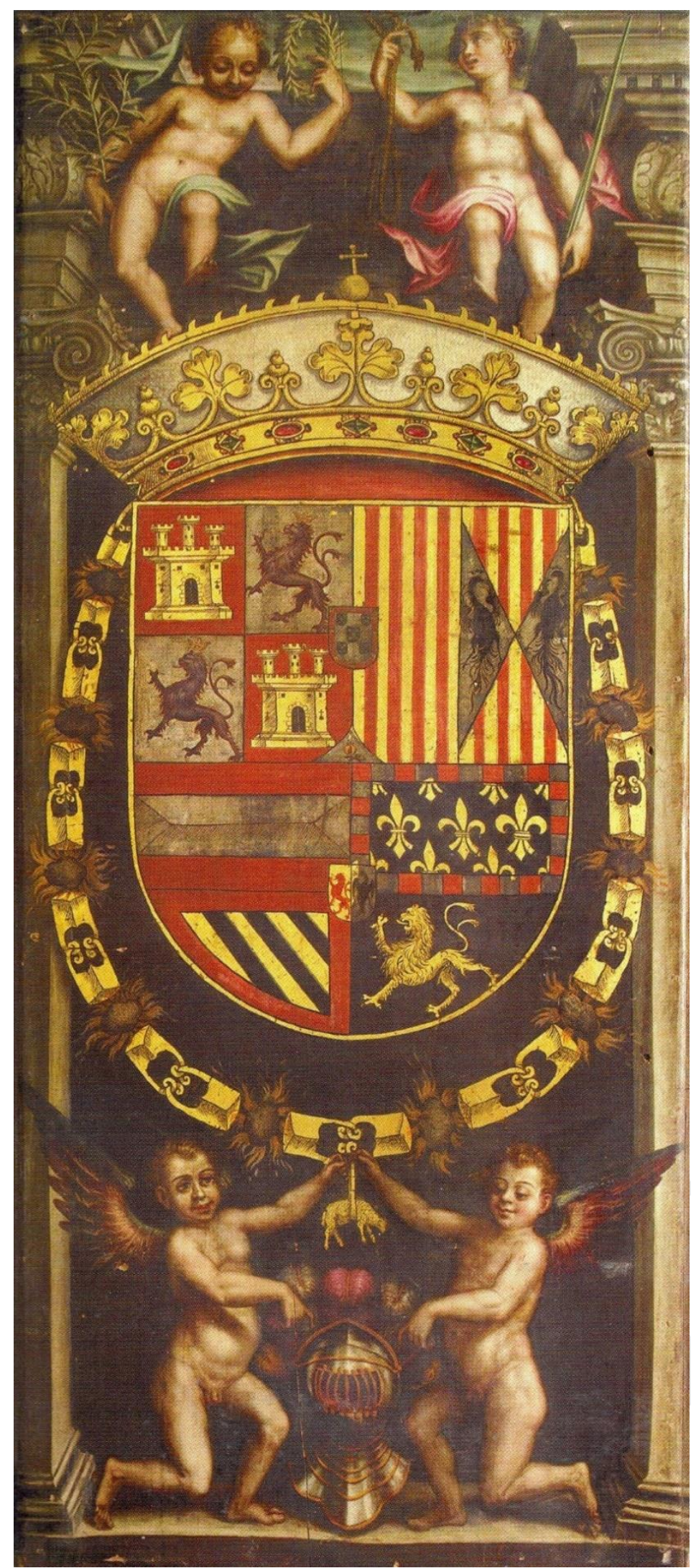

Fig. 4. Martín de Cervera, Heráldica real. Puertas del archivo. Universidad de Salamanca, @ Foto Santiago Santos. 
Hasta donde llegan mis noticias no se había reparado en la figura de la Fe que trasdosa el emblema real, imagen alegórica que acaso ha de relacionarse con las disputas vigentes y los preceptos que se defienden desde la Universidad, muy implicada en los problemas dogmáticos. O tal vez vendría a subrayar la condición pontificia de la institución. Incluso, dado el significado polisémico de las imágenes, pueden contemplar ambos cometidos semánticos. Dada su ubicación, timbrando las puertas del archivo, quizás refiera su misma función: la alegoría de la fe desempeña la labor de legitimar los documentos custodiados; piénsese que el acto de validar un documento se denomina también "dar fe".

\section{A propósito de la epigrafía}

En la parte inferior precisamente debajo del aula de teología y de la alegoría de la Fe, corren unas inscripciones, que constituyen en el sentido literal y metafórico las peanas que sostienen toda la composición, plenas de intención, de hecho. La inscripción apuesta por la grafía latina y letras capitales, se han traducido:

Quae referet nemo triplici tabularia clavi summorum claudunt munera pontificum. [Los archivos que nadie llevaría consigo custodian bajo tres llaves los servicios de los sumos pontífices]

Hoc academia tabulae servantur asylo munera ne regum stat quibus ipsa cadant. [Los registros son conservados por la academia en este lugar inviolable para que no sucumban los privilegios de los reyes en los que ellos se apoyan]

Por su parte, González de Dios confirma la existencia de otras inscripciones:

Aeratis loculis chartas academia servat munera ne regum stat quibus ipsa cadant ${ }^{16}$. [La academia mantiene intactos los papeles en ricas arquillas para que no sucumban los privilegios de los reyes en los que se apoyan $]^{17}$

De partida, la inscripción confirma su carácter inviolable y lo adscribe a un determinado lugar. Refleja igualmente su condición permanente. El término Munera puede aludir tanto a los favores como a los servicios. $Y$ en otro orden de cosas, estas inscripciones solo son visibles cuando se abren las puertas, nótese que es en ese momento entonces cuando pueden extraerse los documentos; actúan por tanto como una advertencia y una exhortación.

16 Juan González de Dios, Index contractus iconem et incriptiones exhibens, quae visuntur in aedibus Salmanticensis Academiae, omnium maximae, (Salamanca: Antonio Joseph Villagordo y Alcaraz, 1759), p. 15.

17 Traducción de la doctora Inmaculada Delgado Jara, a la que agradezco infinitamente su ayuda. 
Conviene "recordar" el valor de la inscripción, constituye un elemento visual, antes que verbal: se da a ver antes que a leer. El recurso al epígrafe delata un evidente valor simbólico, era un símbolo de solemnidad, de ostentación y de poder. Fijada por escrito, es un vehículo de naturaleza perdurable que no sólo tiene trascendencia en el momento concreto, sino que se trasmite para generaciones futuras. En efecto, la escritura además de registrar un mensaje verbal, por estar hecha de signos, es un sistema visual desde un punto semiológico ${ }^{18}$. Posee una función figurativa. La inscripción se coloca en principio en el dominio de lo visual y lo sensible. El texto conmemora y perpetúa la finalidad del mueble, nos informa de su función de archivos y de la naturaleza de los legajos que custodia. Además, la inscripción suscribe un cometido de memoria, un carácter representativo y hasta historiográfico. Un análisis detallado de su contenido denota cómo pivotan ahí los valores de la Universidad salmantina, la condición papal, su autonomía y el apoyo real. La epigrafía actúa como recuerdo, sutilmente trabada y grafiada para que perdure.

De su significado da buena cuenta su destino: las puertas del armario del archivo. De hecho, González de Dios lo identifica como Universitatis Chartophylacium $^{19}$. Se trata en definitiva de aquel lugar donde se guardan y se custodian las esencias de la universidad, y por otra parte las imágenes registran figurativamente esos fundamentos.

En atención a los motivos iconográficos fijados se ha de subrayar el paralelismo que se denota con los ejes centrales de la Portada Rica de la Universidad. En efecto, en ese tapiz petrificado que es la portada se asiste también a la conmemoración de las figuras que han contribuido a su fundación y expansión, los Reyes Católicos en el tondo, con valor emblemático, el escudo del emperador, con carácter heráldico, y en la parte superior la figuración ad vivum del sello universitario, solución que responde a una retórica visual persuasiva y que se podría definir como una escena diplomática, por fijar no solo una carta de partida y también su imaginería habría de desempeñar la misma función que un documento, sellar un pacto ${ }^{20}$. Precisamente este mensaje es el que se promulga en la figuración de las puertas del archivo, dispuesto en todos los registros modales, narrativo, emblemático, heráldico, alegórico y epigráfico. Si la hipótesis se confirma se concretan una serie de relaciones intervisuales, donde unos elementos remiten a otros y de la suma de ellos se entiende y se forja la imagen institucional y su desarrollo a lo largo del tiempo.

\footnotetext{
18 Armando Petrucci, La escritura. Ideología y representación, (Buenos Aires: Ampersand, 2013).

${ }_{19}$ González de Dios, Index contractus iconem, p. 15.

20 Lucía Lahoz, "La portada Rica. Un tapiz petrificado", Universitas. Las artes ante el tiempo. Actas del XXIII Congreso Nacional de Historia del Arte, (Salamanca: Universidad de Salamanca, en prensa)
} 


\section{En torno a su destino y autoría}

La información de la Universidad precisa una serie de movimientos en relación al Archivo, desde 1604 se detectan algunas medidas en esa dirección, en 1604 el claustro encomienda la tarea a Bartolomé Cornejo siendo su hermano Pedro quien le sustituya a su muerte. Se trata de un maestro en Teología, que en 1606 encarga el armario al carpintero Cristóbal de Tolosa, terminado para 1608. De los años 1610 y 1611 se conservan libranzas a favor de Martín de Cervera, pintor y vecino de Salamanca, para el adorno y las armas que pintaba en el archivo ${ }^{21}$. El claustro de diputados de 16 de marzo de 1613 acuerda pagar el salario al pintor Martín de Cervera que "por mandato del M(aestr)o Pedro Cornejo ha pintado el dicho archivo poniendo las armas de la Universidad y su Majestad y otras causas"22. En 1614 aún no se había solucionado el asunto, lo que ha motivado el problema de la cronología y la frecuencia de fecharlo en 1614. De todos modos, del dato se infiere que dado el protagonismo de Pedro Cornejo en la organización del archivo y por su formación, tal vez, sea el promotor del programa iconográfico, o por lo menos uno de ellos. De hecho, como sugiere Teresa Santander ya en 1610 actuaba como comisario.

Su misma ejecución supone un cambio trascendental en cuanto a los ámbitos de custodia del archivo, se supera el modelo arca que había regido desde el principio para adoptar el armario con cajones, buen ejemplo de esos cambios que el aumento de la documentación y la burocracia trajo consigo. Una situación equiparable se constata en el campo de los libros, donde se pasa de las arcas a muebles o librerías propiamente dichas; piénsese en el caso del Colegio de Anaya ${ }^{23}$ o en las noticias del mismo fundador el arzobispo Anaya. ${ }^{24}$

La historiografía las ubica de modo habitual en la sala de manuscritos, pero una interpretación más apurada ha de contemplar su emplazamiento original. Como ha afirmado Jaramillo: "La realización del nuevo mueble y su instalación en un local seguro dedicado exclusivamente para archivo, unido al inventario previo realizado, son todos signos de la madurez que había alcanzado el archivo universitario"25. No es fortuito que originalmente estuviese custodiada en la casa del bedel, y en efecto para ahí se hace el armario y las puertas; en el sentido estricto se trata del archivo universitario y con un espacio propio y específico para él. De partida su condición coincide

\footnotetext{
21 Teresa Santander, "El Archivo Histórico de la Universidad de Salamanca hasta los procesos de informatización", Historia de la Universidad de Salamanca. Vestigios y entramados, T. IV ed. Luis Enrique Rodríguez-San Pedro Bezares, (Salamanca: Ediciones Universidad de Salamanca, 2009), p.53.

22 Libro de Claustro A.U.S.A. 80 fol., 47 r, citado en Vivas, El archivo, p. 124, nota 33.

23 Jorge Jiménez López, "Los espacios del libro en el Colegio Mayor de San Bartolomé" en Espacios en la Edad Media y en el Renacimiento, ed. María Morrás, (Salamanca: Publicaciones de la Semyr, 2018), pp. 211-224 y Jorge Jiménez López, Libros y primer Humanismo en Salamanca. Inventarios y ámbitos del patrimonio librario del Colegio Mayor de San Bartolomé de la Universidad de Salamanca entre 1433 y 1440, (Salamanca: Ediciones Universidad de Salamanca, 2020).

${ }^{24}$ Véase Lucía Lahoz, "Patronato, gusto y devoción del arzobispo de Anaya" en Lienzos del recuerdo. Estudios en homenaje a José María Martínez Frías, eds. Lucía Lahoz y Manuel Hernández Pérez, (Salamanca: Ediciones Universidad de Salamanca, 2015), pp. 298-299.

25 Jaramillo Guerreiro, Archivo, p.179.
} 
con el carácter de tesoro, que entronca con lo romano, vigente a través del mundo hispano medieval. No obstante, es necesario subrayar la idea indicada que, precisamente, pone el foco en que estas pinturas solo eran visibles cuando se abrían las puertas del archivo. Como ya señalara Jaramillo: "Nos dejan bien claras algunas de las características del archivo: su carácter secreto, especialmente protegido y su función primordial de garantizar con esos documentos los privilegios del estudio, sustentados en los poderes reales y pontificios" 26 .

Sin duda, las figuraciones elegidas constituyen el sello universitario, con un despliegue inusitado. La pintura solo es visible cuando el mueble se abre, y habría que apelar al ritual de apertura que, como señala Didi-Huberman, responde al ceremonial aurático, en relación con la dramaturgia ritual de apertura y cerramiento de los retablos ${ }^{27}$. Por otro lado, cuando se abren las puertas, lo primero que se lee es ese carácter inviolable de los legajos. Pero no me resisto a señalar que cuando éstas se cierran, la mayoría de las veces, los motivos fijados, es decir, el sello universitario, viene a sellar el archivo, en el sentido real y metafórico. De ninguna manera me parece fortuito que, primero en el arca y luego en el armario, se debía guardar el sello de la universidad salmantina como estipulaban las constituciones de Benedicto XIII. Y así tenemos las dos caras del sello: la matriz y su impronta custodiando el archivo, subrayando la esencia misma de la institución universitaria.

Y en la casa del bedel se localizó el armario hasta 1719, donde se traslada a un cuarto recientemente habilitado, contiguo al salón grande de la biblioteca o librería antigua, hoy conocido como sala de manuscritos e incunables ${ }^{28}$. No será tampoco ese el emplazamiento definitivo, en 1845 se ubicará en la planta baja de la capilla del Hospital del Estudio ${ }^{29}$. Relativa importancia contiene los datos que confirma Peña Fernández quien describe dos armarios antiguos "donde están pintados, acaso por Juan de Flandes, dos cátedras con sus alumnos y profesores y dos escudos de armas reales de la casa de Austria. La cajonería interior, que es muy elegante y está forrada de chapa, está adornada, con agradables pinturas al óleo, que representan flores y pájaros y recuerda el arte oriental"30. De su significado e importancia da buena cuenta el hecho de que se atribuya a Juan de Flandes; fiel testimonio de su consideración. Finalmente, termina su periplo en los años 1944 cuando vuelve a la sala de manuscritos e incunables, en la remodelación provocada

\footnotetext{
${ }^{26}$ Ibidem.

27 Georges Didi-Huberman, L'imagen ouvert, Motifs de I' Incarnatión dans les arts Visueles, (Paris : Gallimard, 2007), p. 44.

28 Vivas, Archivo, p. 124.

${ }^{29}$ Santander, Archivo, p. 59.

30 Teodoro Peña Fernández, "Archivo", Guía de Salamanca, 2 ed. Imprenta de Manuel Hernández 1904, (1a ed. 1890), p. 55-56. Citado en Vives, Archivo, p. 125, nota 41.
} 
por la devolución de los fondos librarios, hasta ese momento en el Palacio Real de Madrid. ${ }^{31}$

Algunos datos repetidos por la historiografía han de revisarse. Generalmente se otorga a esta obra la fecha de 1614, que necesariamente ha de matizarse, dado que el 13 de marzo el claustro universitario acuerda pagar el salario al pintor Cervera, que por mandato del M(aestr)o Pedro Cornejo (...) ha pintado el dicho archivo, poniendo las armas de la Universidad de su majestad $y$ otras $\operatorname{cosas}^{32}$. Por tanto, ha de desecharse esa fecha de 1614, sin ninguna duda la obra estaba acabada para el 1613, como la documentación ratifica. Una situación equiparable se constata en el emplazamiento original: hoy se dice sin más precisiones que está en la sala de incunables de la Universidad de Salamanca, si bien ese no fue su sitio hasta 1769 , pues originalmente se colocó el armario y por tanto el archivo en la casa del bedel. Luego en la sala baja de la capilla del Hospital para, a partir de 1944, volver a instalarse en la sala de manuscritos e incunables. El dato resulta indicativo de esa necesidad de un esfuerzo de contextualización si se aspira a apurar una idea más exacta del verdadero cometido de estas obras, hoy consideradas artísticas pero que, en su momento, desempeñaron un papel extraordinario que venía a sancionar su verdadero sentido.

En definitiva, con estas puertas del archivo estamos ante un auténtico documento figurativo que detalla la historia universitaria salmantina, imprescindibles para la construcción del relato institucional. Figuración que por todo lo dicho nos proporciona una información preciosa sobre el propio devenir de la universidad, el desarrollo de sus clases y la condición secreta del archivo.

${ }^{31}$ Sobre el traslado de los fondos, Catálogo de manuscritos de la Biblioteca Universitaria de Salamanca. vol. II. Manuscritos 1680-2777, eds. Óscar Lilao Franca, \& Carmen Castrillo González, (Salamanca: Universidad de Salamanca, 2002), p. 14.

${ }^{32}$ Archivo Histórico de la Universidad de Salamanca, Libro de Claustros, 80, fol. 47. 
Bibliografía:

Burke 2001: Peter Burke, Visto y no visto. El uso de la imagen como documento histórico, (Barcelona: Crítica, 2001).

Catálogo de manuscritos 2002: Catálogo de manuscritos de la Biblioteca Universitaria de Salamanca, vol. II. Manuscritos 1680-2777, Óscar Lilao Franca, \& Carmen Castrillo González, eds., (Salamanca: Universidad de Salamanca, 2002).

Didi-Huberman 2007: Georges Didi-Huberman, L'imagen ouvert, Motifs de L'Incarnatión dans les arts Visueles, (Paris: Gallimard, 2007).

Domínguez Casas 2012: Rafael Domínguez Casas, Imago pintiana. Heráldica, Emblemas y Fastos de la Universidad de Valladolid (s. XVI-XXI), (Valladolid: Universidad de Valladolid, 2012).

González de Dios 1759: Juan González de Dios, Index contractus iconem et incriptiones exhibens, quae visuntur in aedibus Salmanticensis Academiae, omnium maximae, (Salamanca: Antonio Joseph Villagordo y Alcaraz, 1759).

Huarte y Echenique 1916: Amalio Huarte y Echenique, El archivo universitario de Salamanca, (Salamanca: Ateneo, 1916).

Jaramillo Guerreiro 2014: Miguel Ángel Jaramillo Guerreiro, "El Archivo de la Universidad de Salamanca: Historia de una larga gestación", en Fuentes, archivos y bibliotecas para una historia de las universidades hispánicas, ed. Luis Enrique Rodríguez-San Pedro Bezares, (Salamanca: Ediciones Universidad de Salamanca, 2014), pp. 161-192.

Jiménez López 2018: Jorge Jiménez López, "Los espacios del libro en el Colegio Mayor de San Bartolomé", en Espacios en la Edad Media y en el Renacimiento, ed. María Morrás, (Salamanca: Publicaciones de la Semyr, 2018), pp. 211-224.

Jiménez López 2020: Jorge Jiménez López, Libros y primer Humanismo en Salamanca. Inventarios y ámbitos del patrimonio librario del Colegio Mayor de San Bartolomé de la Universidad de Salamanca entre 1433 y 1440, (Salamanca: Ediciones Universidad de Salamanca, 2020).

Le Goff 1990: Jacques Le Goff, "Discours de clôture", en Le Travail au Moyen Âge. Une approche interdisciplinaire, Actes du colloque international de Louvain-la-Neuve, mai 1987, Louvain-la-Neuve, (Louvain: Publications de L'Institut d'Etudes Médiévales, 1990) pp. 413-424.

Lahoz Gutiérrez 2008: Lucía Lahoz Gutiérrez, "Puerta de la sala de manuscritos (Martín de Cervera)", en El Barroco en Salamanca, eds. José María Martínez Frías, Manuel Hernández Pérez y Lucía Lahoz, (Salamanca: Junta Castilla y León, 2008), p. 104.

Lahoz Gutiérrez 2012: Lucía Lahoz Gutiérrez, "La primera imagen universitaria salmantina, ¿Entre la vindicación pontificia y la poética 
mudéjar?", en Imagen, contextos morfológicos y universidades. Miscelánea Alfonso IX, eds. L. E. Rodríguez San Pedro-Bezares y J. L. Polo Benito, (Salamanca: Universidad de Salamanca, 2012), pp. 69-119.

Lahoz Gutiérrez 2014: Lucia Lahoz Gutiérrez, "La imagen de la universidad Pontificia" en La universidad de Salamanca y el pontificado en la Edad Media, eds. Miguel Anxo Pena González y Luis Enrique Rodríguez-San Pedro, (Salamanca: Universidad Pontificia de Salamanca, 2014), pp. 483-532.

Lahoz Gutiérrez 2015: Lucía Lahoz Gutiérrez, "Patronato, gusto y devoción del arzobispo de Anaya" en Lienzos del recuerdo. Estudios en homenaje a José María Martínez Frías, eds. Lucía Lahoz y Manuel Hernández Pérez, (Salamanca: Ediciones Universidad de Salamanca, 2015), pp. 298-299.

Lahoz Gutiérrez (2021): Lucía Lahoz Gutiérrez, "La portada Rica. Un tapiz petrificado", en Universitas. Las artes ante el tiempo. Actas del XXIII Congreso Nacional de Historia del Arte, (Salamanca: Universidad de Salamanca, en prensa)

Mazin Gómez 1999: Óscar Mazin Gómez, "Presentación. Las imágenes y el historiador", Relaciones, 77, Vol. XX, (1999), pp. 11-14.

Montaner López 1987: Emilia Montaner López, Pintura barroca en Salamanca, (Salamanca: Ediciones Universidad de Salamanca, 1987).

Muñoz Gómez 2019: Elena Muñoz Gómez, "Tapicería troyana en Zamora... 'Y otras cosas ançianas que hayan sido de nuestros abuelos y bisabuelos'", en Humanistas, helenistas y hebraístas en la Europa de Carlos V, coords. Miguel Anxo Pena González e Inmaculado Delgado Jara, (Salamanca: Universidad Pontificia de Salamanca, 2019), pp. 410-437.

Petrucci 2013: Armando Petrucci, La escritura. Ideología y representación, (Buenos Aires: Ampersand, 2013).

Pereda Espeso 2000: Felipe Pereda Espeso, La arquitectura elocuente. El edificio de la Universidad de Salamanca bajo el reinado de Carlos V, (Madrid: Sociedad Estatal para la Conmemoración de los Centenarios de Felipe II y Carlos V, 2000).

Rodríguez-San Pedro 2001: Luis Enrique Rodríguez-San Pedro Bezares, "Vida estudiantil en el siglo de Oro" en Estudiantes de Salamanca, eds. Luis Enrique Rodríguez-San Pedro Bezares y Roberto Martínez del Río, (Salamanca: Ediciones Universidad de Salamanca, 2001), p. 60.

Santander Rodríguez 2009: Teresa Santander Rodríguez, "El Archivo Histórico de la Universidad de Salamanca hasta los procesos de informatización", en Historia de la Universidad de Salamanca. Vestigios y entramados, ed. Luis Enrique Rodríguez-San Pedro Bezares, T. IV (Salamanca: Ediciones Universidad de Salamanca, 2009), pp. 51-82.

Schapiro 1996: Meyer Schapiro, Palabras, escritos e imágenes, (Madrid: Ed. Encuentro, 1996). 
Vivas Moreno 1999, Agustín Vivas Moreno, "El Archivo Histórico de la Universidad de Salamanca: Historia y procedencias documentales", en Documentación de las ciencias de información, n² 22, (1999), pp. 117-148.

Recibido: $23 / 03 / 2021$

Aceptado: $28 / 04 / 2021$ 